\title{
An Experimental Augmented Reality Platform for Assisted Maritime Navigation
}

\author{
Olivier Hugues \\ MaxSea - ESTIA Recherche \\ Bidart France \\ +33559417096 \\ o.hugues@net.estia.fr
}

\author{
Jean-Marc Cieutat \\ ESTIA Recherche \\ Bidart, France \\ +33559438475 \\ j.cieutat@estia.fr
}

\author{
Pascal Guitton \\ University Bordeaux 1 (LaBRI) \& INRIA \\ Bordeaux, France \\ +33540006918 \\ guitton@labri.fr
}

\begin{abstract}
This paper deals with integrating a vision system with an efficient thermal camera and a classical one in maritime navigation software based on a virtual environment (VE). We then present an exploratory field of augmented reality (AR) in situations of mobility and the different applications linked to work at sea provided by adding this functionality. This work was carried out thanks to a CIFRE agreement within the company MaxSea Int.
\end{abstract}

\section{Categories and Subject Descriptors}

H.5.1 [Information Interfaces and Presentation]: Multimedia Information Systems - Artificial, augmented and virtual realities; I.3.7 [Computer Graphics]: Three-Dimensional Graphics and Realism-Virtual reality.

\section{General Terms}

Experimentation, Human Factor, Security.

\section{Keywords}

Augmented Reality, Mixed Environment, Image Processing, Human Factor, Combining exteroceptive data.

\section{INTRODUCTION}

The continuous progress of new technologies has led to a proliferation of increasingly smart and powerful portable devices. The capabilities of devices on board a ship now enable crews to be offered a processing quality and volume of information until now unrivalled. In a hostile environment such as the sea, users need a relevant flow of information. Computer assisted vessel management is therefore increasingly widespread and digitalisation is an inescapable development. The three main aims are as follows:

1. Improved safety (property, environment and people)

2. Increased gains from productivity (fishing, etc)

3. The representations required for environmental control (orientation, location and direction)
These aims have led maritime software publishers to develop increasingly sophisticated platforms, offering very rich virtual environments and real time information updates. There are many companies on the embedded maritime navigation software market. They can be separated into two categories. The first part includes those, which develop applications enabling embedded sensors to be taken advantage of (radar, depth-finder, GPS, etc.), such as Rose Point [4], publisher of Coastal Explorer software (Figure 3) and MaxSea International [14], publisher of the MaxSea TimeZero software (Figure 2). Other companies offer hardware platforms in addition to their software applications, like Furuno [10] (Figure 4) and Garmin [11] (Figure 1).

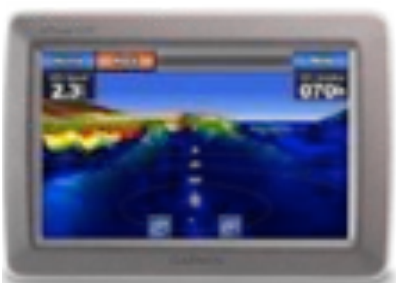

Figure 1. Garmin

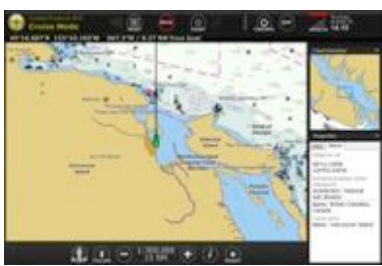

Figure 3. Coastal Explorer

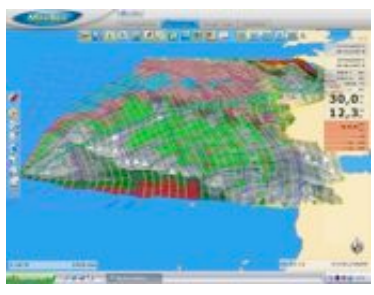

Figure 2. MaxSea

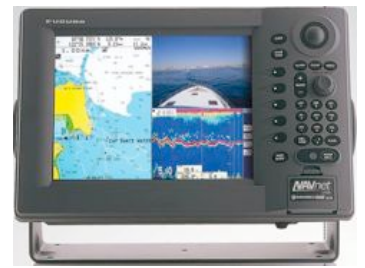

Figure 4. Furuno
These environments enable navigation to be greatly improved by only showing the necessary information, eg. by combining satellites photos of the earth and nautical charts like PhotoFusion in Figure 5 proposed by MaxSea [14].

personal or classroom use is granted without fee provided that copies are not made or distributed for profit or commercial advantage and that copies bear this notice and the full citation on the first page. To copy otherwise, to republish, to post on servers or to redistribute to lists, requires prior specific permission and/or a fee.

Augmented Human Conference, April 2-3, 2010, Megève, France.

Copyright $\odot 2010$ ACM 978-1-60558-825-4/10/04 ..\$10.00. 